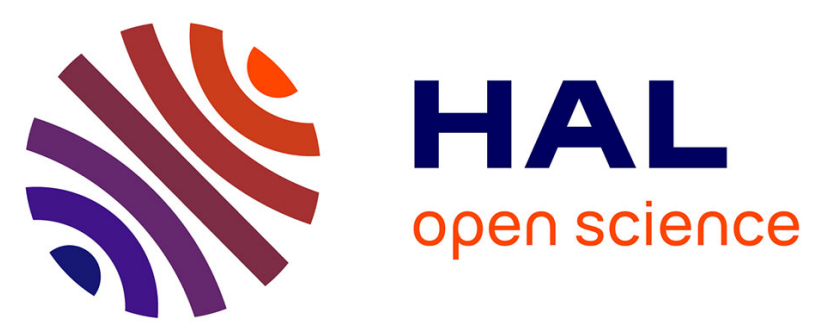

\title{
Investigation of the invasion mechanism mediated by the outer membrane protein PagN of Salmonella Typhimurium
}

Emilie Barilleau, Mégane Védrine, Michael Koczerka, Julien Burlaud-Gaillard, Florent Kempf, Olivier Grépinet, Isabelle Virlogeux-Payant, Philippe Velge, Agnès Wiedemann

\section{To cite this version:}

Emilie Barilleau, Mégane Védrine, Michael Koczerka, Julien Burlaud-Gaillard, Florent Kempf, et al.. Investigation of the invasion mechanism mediated by the outer membrane protein PagN of Salmonella Typhimurium. BMC Microbiology, 2021, 21 (1), 18 p. 10.1186/s12866-021-02187-1 . hal-03234143

\author{
HAL Id: hal-03234143 \\ https://hal.inrae.fr/hal-03234143
}

Submitted on 25 May 2021

HAL is a multi-disciplinary open access archive for the deposit and dissemination of scientific research documents, whether they are published or not. The documents may come from teaching and research institutions in France or abroad, or from public or private research centers.
L'archive ouverte pluridisciplinaire HAL, est destinée au dépôt et à la diffusion de documents scientifiques de niveau recherche, publiés ou non, émanant des établissements d'enseignement et de recherche français ou étrangers, des laboratoires publics ou privés. 


\title{
Investigation of the invasion mechanism mediated by the outer membrane protein PagN of Salmonella Typhimurium
}

Emilie Barilleau', Mégane Védrine ${ }^{1,2}$, Michael Koczerka', Julien Burlaud-Gaillard, Florent Kempf ${ }^{1}$, Olivier Grépinet ${ }^{1}$, Isabelle Virlogeux-Payant ${ }^{1}$, Philippe Velge ${ }^{1}$ and Agnès Wiedemann ${ }^{1,4^{*}}$

\begin{abstract}
Background: Salmonella can invade host cells via a type three secretion system called T3SS-1 and its outer membrane proteins, PagN and Rck. However, the mechanism of PagN-dependent invasion pathway used by Salmonella enterica, subspecies enterica serovar Typhimurium remains unclear.

Results: Here, we report that PagN is well conserved and widely distributed among the different species and subspecies of Salmonella. We showed that PagN of S. Typhimurium was sufficient and necessary to enable noninvasive E. coli over-expressing PagN and PagN-coated beads to bind to and invade different non-phagocytic cells. According to the literature, PagN is likely to interact with heparan sulfate proteoglycan (HSPG) as PagN-mediated invasion could be inhibited by heparin treatment in a dose-dependent manner. This report shows that this interaction is not sufficient to allow the internalization mechanism. Investigation of the role of $\beta 1$ integrin as coreceptor showed that mouse embryo fibroblasts genetically deficient in $\beta 1$ integrin were less permissive to PagNmediated internalization. Moreover, PagN-mediated internalization was fully inhibited in glycosylation-deficient pgsA-745 cells treated with anti- $\beta 1$ integrin antibody, supporting the hypothesis that $\beta 1$ integrin and HSPG cooperate to induce the PagN-mediated internalization mechanism. In addition, use of specific inhibitors and expression of dominant-negative derivatives demonstrated that tyrosine phosphorylation and class I phosphatidylinositol 3-kinase were crucial to trigger PagN-dependent internalization, as for the Rck internalization mechanism. Finally, scanning electron microscopy with infected cells showed microvillus-like extensions characteristic of Zipper-like structure, engulfing PagN-coated beads and E. coli expressing PagN, as observed during Rck-mediated internalization.
\end{abstract}

Conclusions: Our results supply new comprehensions into T3SS-1-independent invasion mechanisms of $S$. Typhimurium and highly indicate that PagN induces a phosphatidylinositol 3-kinase signaling pathway, leading to a Zipper-like entry mechanism as the Salmonella outer membrane protein Rck.

Keywords: Salmonella, Outer membrane protein, PagN, Invasion, Actin, Zipper-like entry pathway

\footnotetext{
* Correspondence: agnes.wiedemann@inrae.fr

'INRAE, Université de Tours, ISP, F-37380 Nouzilly, France

${ }^{4}$ Present Address: IRSD - Institut de Recherche en Santé Digestive, Université de Toulouse, INSERM, INRAE, ENVT, UPS, Toulouse, France

Full list of author information is available at the end of the article
}

(C) The Author(s). 2021 Open Access This article is licensed under a Creative Commons Attribution 4.0 International License, which permits use, sharing, adaptation, distribution and reproduction in any medium or format, as long as you give appropriate credit to the original author(s) and the source, provide a link to the Creative Commons licence, and indicate if changes were made. The images or other third party material in this article are included in the article's Creative Commons licence, unless indicated otherwise in a credit line to the material. If material is not included in the article's Creative Commons licence and your intended use is not permitted by statutory regulation or exceeds the permitted use, you will need to obtain permission directly from the copyright holder. To view a copy of this licence, visit http://creativecommons.org/licenses/by/4.0/. The Creative Commons Public Domain Dedication waiver (http://creativecommons.org/publicdomain/zero/1.0/) applies to the data made available in this article, unless otherwise stated in a credit line to the data. 


\section{Background}

Salmonella is a Gram-negative bacterium, belonging to the Enterobacteriaceae family. This genus is divided into two species: S. bongori and S. enterica. The latter consists of six subspecies: indica, diarizonae, arizonae, salamae, houtenae, and enterica [1]. Currently, more than 2600 Salmonella serovars have been identified [2]. Warm-blooded animals are mainly infected by strains belonging to S. enterica subsp. enterica [3]. Depending on the host and the serotype, Salmonella leads to a wide variety of diseases ranging from gastroenteritis to systemic typhoid fever in both animals and humans. Salmonella is spread by the fecal-oral route and can be transmitted through contaminated water and food. After Salmonella ingestion, the bacteria are found in the intestine, where they are able to adhere to the intestinal epithelium and to induce their own entry into host cells. This allows Salmonella colonization of the intestinal tract, which constitutes a crucial step in establishing infection [2]. To invade non-phagocytic cells, Salmonella expresses several invasion factors: a type III secretion system (T3SS) known as T3SS-1, and two invasins Rck and PagN [4].

For many pathogenic bacteria, T3SS are essential virulence factors composed of several substructures that organize into one needle-like structure called an injectisome. This apparatus serves as an entrance for the bacterial secreted effectors to pass through the inner and outer membranes of the bacterium. When Salmonella reaches the small intestine, a neutral $\mathrm{pH}$, a low $\mathrm{O}_{2}$ tension, high osmolarity and a high iron concentration induce SPI-1 expression. In contrast, the presence of cationic peptides or bile suppresses its expression. The T3SS-1 allows the injection of bacterial effector proteins directly into the host cell. This promotes massive actin polymerization and ruffles membrane rearrangements, leading to bacterial internalization. This invasion mechanism is described as a Trigger mechanism. The contribution of the T3SS-1 in Salmonella pathogenesis has been demonstrated but depends on the host [5].

The outer membrane protein Rck (resistance to complement killing) is encoded by the $r c k$ open reading frame localized on the virulence plasmid [6]. The transcription of $S$. Typhimurium $r c k$ gene is regulated by SdiA, a quorum sensing regulator [7], which is activated by acyl homoserine lactones (AHL) produced by other bacteria [8,9]. The Rck outer membrane protein of $S$. Enteritidis is able to interact with EGFR (epidermal growth factor receptor) expressed on the host cell surface, allowing bacterial invasion [10, 11]. A 46 aminoacid region (from G114 to V159) has been shown to be necessary and sufficient to induce the $S$. Enteritidis invasion mechanism [10]. Between the Rck proteins of $S$. Enteritidis and $S$. Typhimurium, this region is very well preserved except for one amino acid substitution (His to Arg) at position 125. The invasion mechanism induced by Rck of $S$. Enteritidis requires induction of a cellular transduction pathway, which has been well characterized. This includes phosphorylation of tyrosine proteins, and activation of PI 3-kinase (phosphatidylinositol 3kinase), leading to actin polymerization and weak membrane rearrangement $[10,12,13]$. This invasion mechanism is described as a Zipper mechanism [10]. Rck of $S$. Typhimurium is able to induce the bacterial invasion mechanism [14]. However, the signaling cascade leading to the bacterial internalization has not been characterized. The involvement of Rck-EGFR interaction in Salmonella pathogenesis remains unclear. However, a $S$. Typhimurium infection performed in a mouse model of intestinal persistence (an asymptomatic carrier state model) demonstrated that Rck was important for the fitness of Salmonella in the intestine [15].

The outer membrane protein, PagN (phoP-activated gene), has also been identified as a Salmonella invasin $[16,17]$. It was first identified in $S$. Typhimurium using a $\operatorname{Tn} p h o A$ random-insertion screening designed to identify PhoP-activated genes [18]. The pagN gene is localized on the specific centisome 7 genomic island and is present in most serotypes that have been tested [19-21]. The transcription of pagN is regulated by the twocomponent transcriptional regulatory $\mathrm{PhoP} / \mathrm{PhoQ}$ system. In response to an acidified environment, low $\mathrm{Mg}^{2+}$ concentration or the presence of antimicrobial peptides, PhoQ is auto-phosphorylated and transfers its phosphate to the cytoplasmic DNA-binding protein PhoP that induces or represses the transcription of specific Salmonella genes [22]. Lambert et al. were the first to demonstrate that pagN deletion in $S$. Typhimurium led to a reduction in Salmonella invasion of enterocytes [16, 21]. However, the PagN-mediated invasion mechanism remains poorly characterized at the cellular level. The only information known is that actin polymerization is required for promoting PagN-induced bacterial invasion [17] and that PagN uses extracellular heparan sulfate proteoglycans (HSPG) to invade cells [17]. Concerning the role of PagN in Salmonella pathogenesis, several studies have shown that in vivo, a $S$. Typhimurium pagN mutant strain (i) induces less pathological signs in the intestine and survives longer compared to its parental strain in streptomycin-treated mice after oral inoculation and (ii) colonizes the spleen of $\mathrm{BALB} / \mathrm{c} / \mathrm{C}$ mice less than the wild-type strain after intra-peritoneal inoculation [21, 23].

In this study, we first took advantage of the large number of Salmonella genomes available in Enterobase to revisit the distribution of PagN among the Salmonella genus. We investigated the link between HSPG and the PagN-mediated internalization mechanism and then 
characterized the signaling pathway induced during the PagN invasion mechanism of $S$. Typhimurium within host cells to compare it to the mechanism triggered during the Rck-mediated invasion pathway.

\section{Results}

PagN invasin is widely distributed and well conserved among the different species and subspecies of Salmonella The presence of the pagN ORF was previously studied in only a limited number of Salmonella strains belonging to the different species, subspecies and serotypes [19-21, 24]. We took advantage of the great number of Salmonella genomes available in the extensive Enterobase database to reconsider the distribution of this gene and to study its allele and protein diversity within the Salmonella genus (S. bongori and S. enterica). Consistent with previous works, pagN was found at a very high frequency in all $S$. enterica subspecies as well as in $S$. bongori species. The percentage of strains harbouring the pagN gene ranged from $99.069 \%$ for subspecies S. enterica subsp. salamae to $100 \%$ for S. bongori and S. enterica subspecies houtenae and indica (Fig. 1a). A total of 944 allelic variants of the pagN ORF were observed, ranging from 700 to 755 nucleotides in length. The allele designated as No. 1 was found to be the most represented within the Salmonella genus in the database $(42.02 \%$ of the recorded genomes). Thus, it was chosen as a reference for all sequence comparisons presented in this section. We then analyzed the distribution of pagN allelic variants within $S$. bongori and the six subspecies of Salmonella enterica (Fig. 1a). For S. bongori, we measured a haplotype diversity index of 0.923 , which is relatively high. We found 28 different alleles of the gene, each of them presenting low frequencies $(f<0.1)$ except the allele designated as No. $51(\mathrm{f}=0.216)$. It is interesting to note that only 4 of the 28 allelic variants were shared with the $S$. enterica species. Strains of the non-enterica subspecies of $S$. enterica present various haplotype diversity; we found 69, 33, 24, 23 and 5 alleles for S. enterica subsp. salamae, S. enterica subsp. arizonae, S. enterica subsp. diarizonae, S. enterica subsp. houtenae, and $S$. enterica subsp. indica, respectively. This allelic richness is not related to the number of genomes available for each subspecies. This could explain the variation in the calculated haplotype diversity indexes. However, independently of this diversity, a predominant allele was found in each subspecies; S. arizonae was mainly associated with allele No. $110(\mathrm{f}=0.417), S$. diarizonae with allele No. $3(\mathrm{f}=0.538), S$. houtenae with allele No. 193 ( $\mathrm{f}=0.613)$ and $S$. indica with allele No. $87(\mathrm{f}=0.640)$. It should be noted that these alleles are specific to these subspecies, as none of these predominant alleles were found in another species or subspecies except allele No. 3 , which was found in 3 genomes belonging to subspecies enterica. Moreover, the other allelic variants of the gene were rarely shared between non-enterica Salmonella enterica subspecies, as only alleles No. 63 and No. 91 were found on two of them (subsp. arizonae and houtenae).

Finally, for S. enterica subsp. enterica we measured a relatively high haplotype diversity index of 0.803 . Possibly due to the number of available genomes, this subspecies presents the highest number of variants in our sample: 781 alleles are found for this subspecies in the dataset (Fig. 1a) and allele No. 1 is the predominant one $(\mathrm{f}=0.424)$. Other alleles always present low frequencies $(\mathrm{f}<0.1)$ in that sample. Moreover, among the 781 allelic variants, only 17 of them $(2.17 \%)$ are found in genomes belonging to $S$. bongori species and to other subspecies. Genomes carrying these shared allelic variants belong to a panel of 60 serovars, each showing very different levels of specificity for these variants, their frequencies ranging from 0.0001 to 1 . Amino-acid sequences of the predominant alleles of $S$. bongori and non-enterica subspecies of S. enterica were compared to the translated sequence of allele No. 1. They all have a very high percentage of identity with our reference allele (ranging from 82.8 to 95.0\%), thus highlighting a high conservation of the PagN protein in the Salmonella genus (data not shown).

We next investigated the distribution of pagN allelic variants among the 20 most frequently isolated Salmonella enterica subsp. enterica serovars in humans in Europe in 2017 [25]. It should be noted that genomes of three of these serovars, i.e. serovars Naples, Java and Kottbus, were not available in Enterobase when the genomes were retrieved for our study. This represented 112,662 genomes, in which 268 alleles were identified. Among these allelic variants, 240 were serovar-specific. Given the low distribution of some allelic variants in this dataset, we only considered the allelic variants carried by at least $1 \%$ of the strains in at least one of these 17 serovars for subsequent analysis. This represented a total of 40 alleles of the pagN gene (covering $98.53 \%$ of the 112, 662 selected genomes). Under this scheme, we observed that 11 out of the 17 serovars were predominantly associated with one allele. For example, allele designated as No. 1 was found at very high frequencies in genomes of $S$. Enteritidis $(f=0.988)$ and of the monophasic variant of $S$. Typhimurium (antigenic formula: 4;[5];12:i:-) (f= $0.993)$ strains, as well as allele No. 10 that was found at similar frequencies in $S$. Infantis genomes $(\mathrm{f}=0.993)$. On the other hand, we also observed other serovars associated with a larger range of alleles, such as $S$. Newport, $S$. Virchow or $S$. Bareilly, consequently showing higher haplotype diversity indexes (Fig. 1b). The amino acid sequence alignment of these 40 allelic variants showed high identity with allele No. 1, ranging from 98.7 to $100 \%$ (Fig. 1b). 
A

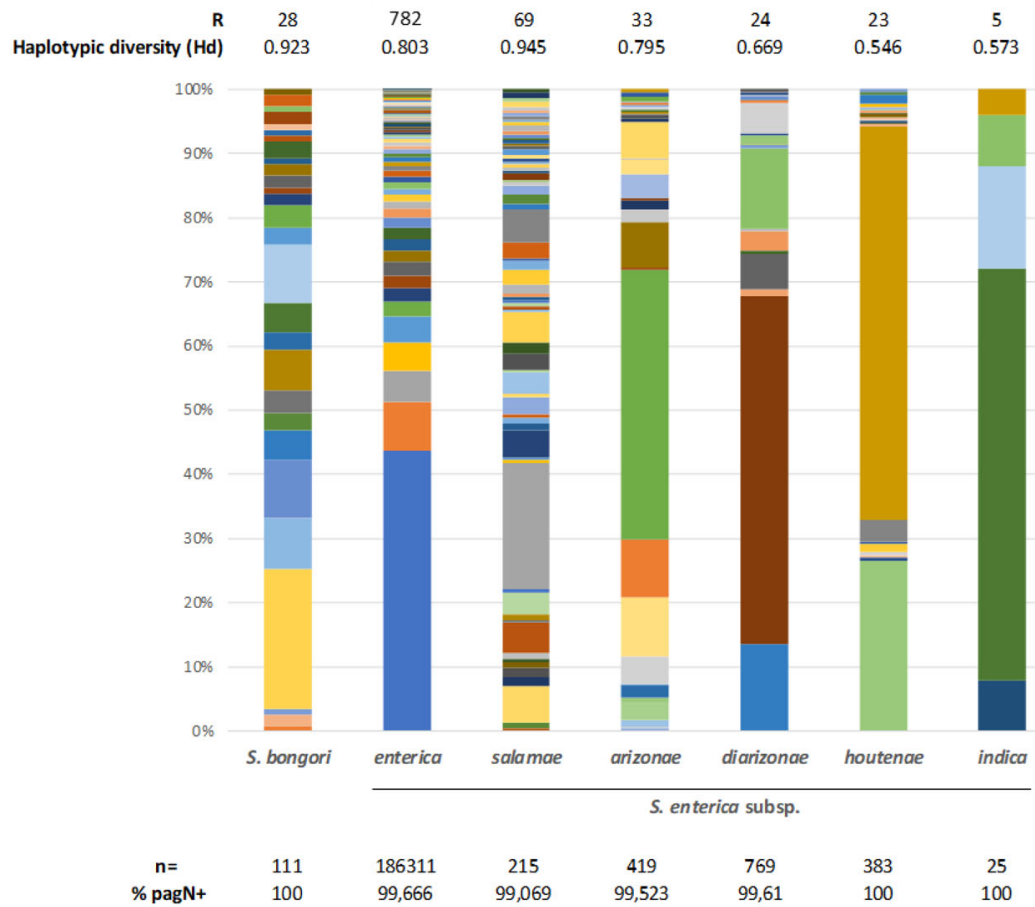

B

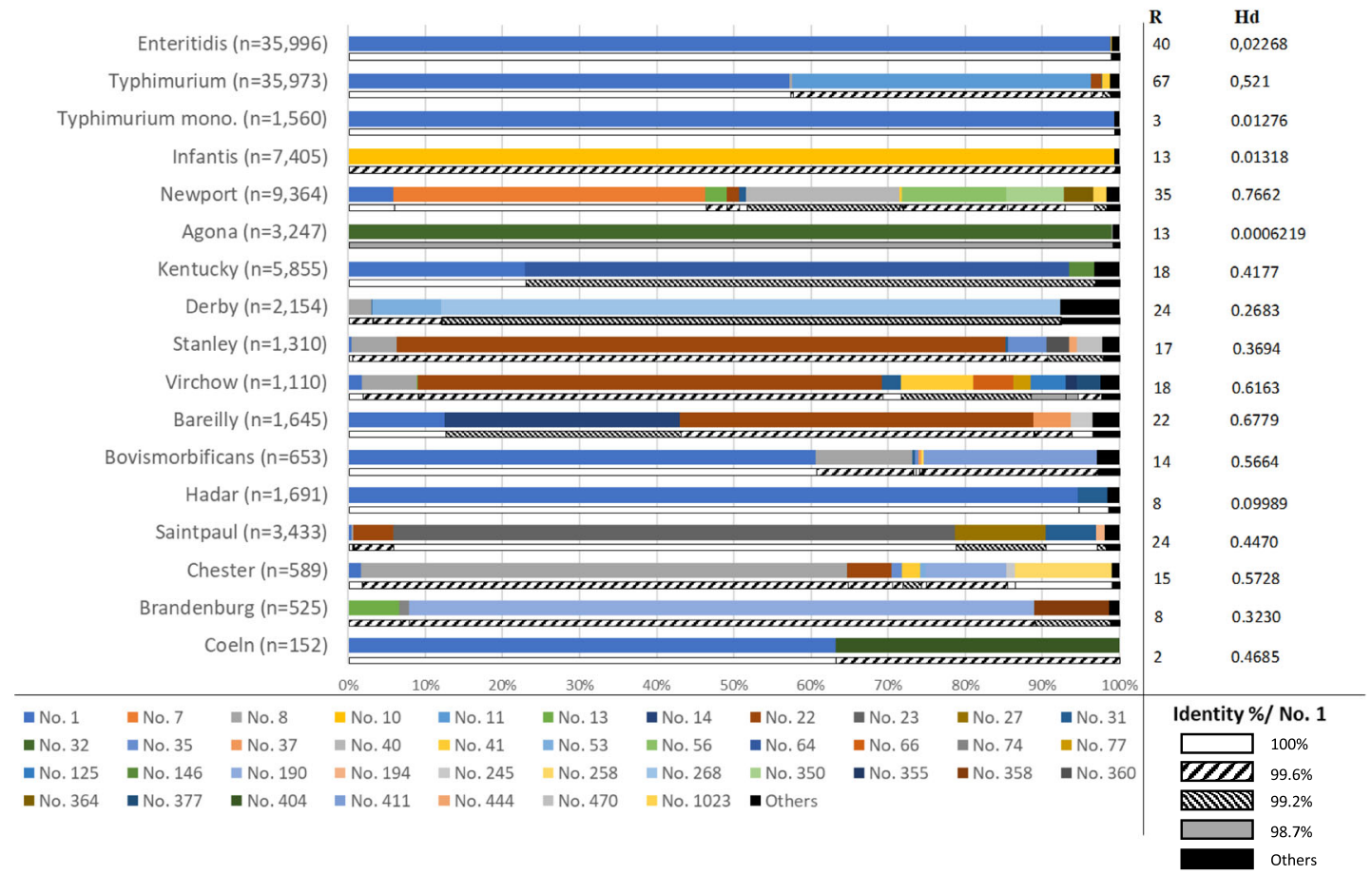

Fig. 1 (See legend on next page.) 
(See figure on previous page.)

Fig. 1 Distribution of allelic variants of pagN within Salmonella genus. a The distribution of pagN allelic variants was determined within subspecies enterica, salamae, arizonae, diarizonae, houtenae, indica and species bongori. Richness (R) and haplotype diversity (Hd) was measured to evaluate polymorphism. Each colour represents an allelic variant. $\mathrm{n}$ represents the number of genomes for each species/subspecies. $\mathbf{b}$ Distribution of pagN allelic variants within 17 out of the 20 most isolated serovars in Europe in 2017. $\mathrm{n}$ corresponds to the number of genomes for each serovar. We considered the alleles found in $>1 \%$ of the strains in a given serovar. Each allele was designated by the number used in Enterobase. Each colour represents an allelic variant, except black which corresponds to the variants showing frequencies under 0.01 for these serovars. Except for the allelic variants showing frequencies under 0.01 , the identity percentages were calculated using the protein encoded by allele designated as No. 1 set as reference

Taken together, these results confirm that $\operatorname{pagN}$ is widely distributed within the Salmonella genus, and demonstrate that the encoded protein is well conserved among species, subspecies and serovars. They also highlight some allelic specificity at the species, subspecies and serovar levels. This high conservation of PagN suggests an ubiquitous role of this protein, independent of the strain serovar-specificity, and of the pathogenic potential of the strains toward their hosts, although we cannot exclude that some substitutions could be responsible for these phenotypes.

\section{PagN-mediated invasion mechanism depends on the host} cell line

PagN of $S$. Typhimurium has previously been shown to mediate both adhesion to and invasion of $\mathrm{CHO}$ cells [16]. Prior to characterizing the invasion mechanism mediated by PagN, we first decided to confirm these results. PagN of $S$. Typhimurium was chosen and a non-invasive E. coli HB101 strain harboring either pSUP202 (HB101-psup) or pSUP202-PagN $(H B 101-p a g N)$ was used as standard in vitro culture conditions are not suitable for PagN production by $S$. Typhimurium [22]; Holbert et al. unpublished]. The percentage of total cell-associated and internalized bacteria was determined using standard adhesion and invasion assays. As shown in Fig. 2, we observed that the percentage of total cell-associated and internalized HB101-pagN strain was increased 2- and 400-fold, respectively compared to the control strain (HB101-psup). Our results confirm that PagN is able to induce bacterial adhesion to and invasion of epithelial cells.

Lambert and Smith showed that PagN utilizes HSPG to invade mammalian cells [17]. HSPG are membraneanchored proteins with covalently attached glycosaminoglycan side-chains consisting of heparan sulfate (HS) [26]. In order to characterize better the role of HSPG in PagN-mediated invasion, we first determined the

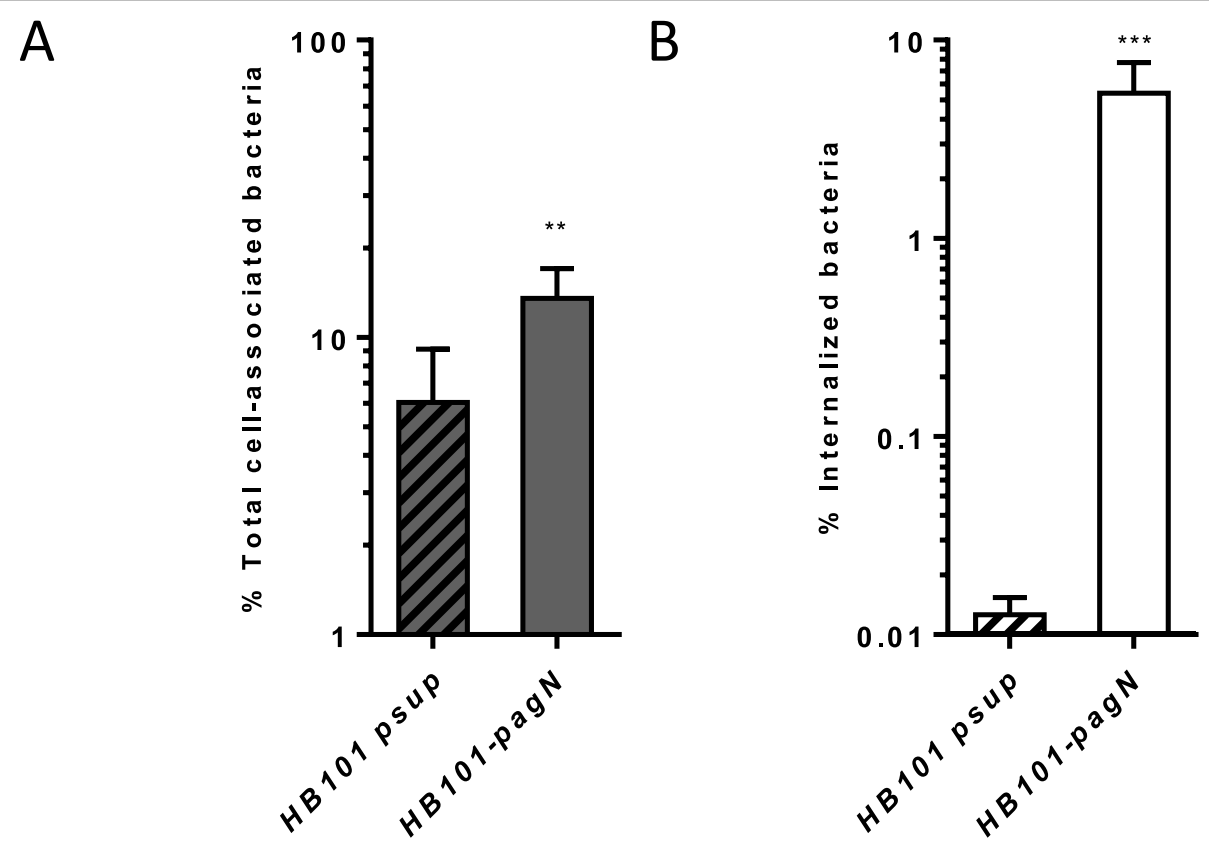

Fig. 2 PagN is able to induce both adhesion and invasion depending on the cell line. CHO cells were infected with HB101-psup (hatched bars) or HB101-pagN strain (empty bars) at $37^{\circ} \mathrm{C}$ for $1 \mathrm{~h}(\mathrm{MOI}$ 1:10). The percentages of total cell-associated (a) and internalized (b) bacteria have been calculated as described in Materials and Methods. Data show mean values \pm SD acquired from three independent experiments with two infected wells per experiment. Data were compared using a Mann Whitney test $\left({ }^{* *} p<0.001,{ }^{* *} p<0.01\right)$ 
expression of HS on the cell surface of different cell lines by flow cytometry using a specific monoclonal anti-HS antibody. The different cell lines chosen were: (i) Caco2 cells, which are mainly used to study the intestinal invasion of Salmonella [27]; (ii) HT29 and CHO cell lines as they were previously used to study PagN-mediated invasion mechanism [16, 21]; (iii) proteoglycan-deficient $\mathrm{CHO}$ cell line (pgsA745 cells) as a control. The mean percentage of HS positive (HS+) cells showed that HS were detectable on the surface of each cell line but at different levels. As shown in Fig. 3a, the mean percentage of $\mathrm{HS}+$ cells is similar in $\mathrm{CHO}$ and $\mathrm{Caco} 2$ cells, while it is significantly lower in pgsA745 cells and higher in HT29 cells. Next, the ability of HB101-pagN to invade these different cell lines was measured. As expected, we observed that the mean percentage of internalized HB101-pagN was 1000-fold lower in pgsA745 than $\mathrm{CHO}$ cells, confirming the results of Lambert et al [17]. Surprisingly, the percentage of internalized bacteria was identical in Caco2 and pgsA745 cells and 10,000-fold lower in HT29 cells than in pgsA745 cells (Fig. 3b). These results demonstrated that the invasion ability of an E. coli strain expressing PagN is not related to the HS exposed on the host cell surface.

Taken together, these data demonstrate that PagN is able to mediate cell invasion but regardless of the HS, suggesting that HSPG are involved but not sufficient to allow the invasion mechanism mediated by PagNmediated invasion.

\section{PagN-mediated internalization requires $\beta 1$ integrin}

According to the literature, HSPG may act as coreceptors for downstream cellular signaling events triggered by integrins $[28,29]$. To assess the role of $\beta 1$ integrin in PagN-mediated invasion, cells that were deficient for $\beta 1$ chain integrin production were used. F9 cells carry three copies of the gene encoding the $\beta 1$ integrin chain, and TKO (triple knockout) cells fail to express $\beta 1$ integrin chain due to insertions in each of the three copies. DKO (double knockout) cells retain one intact copy of the $\beta 1$ integrin gene and thus retain production of $\beta 1$ integrins [30]. Targeted deletion of $\beta 1$ integrins in F9 cells affects morphological differentiation but not tissue-specific gene expression. As control, an $E$. coli MC1061 strain which overexpresses the Yersinia enterocolitica Invasin protein (MC-InvGFP) allowing binding to $\beta 1$ integrin receptor and subsequent invasion into mammalian cells was used [31]. The ability of HB101-pagN and MC-InvGFP to bind to and invade F9, TKO and DKO cells was thus compared. As expected, Invasin-expressing strain was able to adhere and invade more efficiently cells expressing $\beta 1$ integrin receptor (Fig. 4). As shown in Fig. 5b, the percentage of internalized HB101-pagN was significantly higher in F9, and DKO cells, expressing $\beta 1$ integrin than in TKO cells, Indeed, an 8- and 5-fold decrease in invasion was observed in TKO cells compared to the other two cell lines, respectively. In contrast, the absence of $\beta 1$ integrin resulted in similar level of the total number of cellassociated bacteria (Fig. 5a). This provides evidence that PagN-mediated internalization but not adhesion depends on $\beta 1$ integrin.

The involvement of $\beta 1$ integrin in PagN-mediated internalization led us to investigate the cooperation of HSPG and $\beta 1$ integrin in this process. To this end, the ability of HB101-pagN to invade pgsA745 cells pre-
A



B

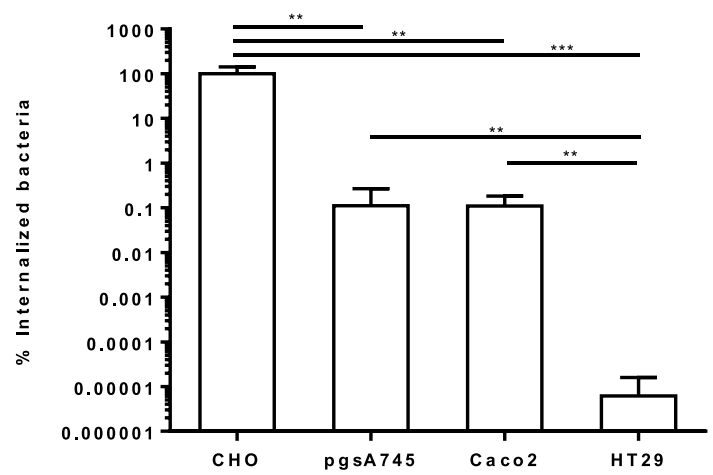

Fig. 3 The presence of heparan sulfate is not correlated to the level of PagN-mediated internalization. a The distribution of HS was analyzed on the cell surface of $\mathrm{CHO}$, pgsA745, Caco-2 and HT29 cell lines by flow cytometry using a specific anti-HS antibody. The percentage of HS positive (HS+) cells was calculated using histogram subtraction (method of Overton) for each cell line as described in the Materials and Methods. b CHO, pgsA745 and Caco-2 cells were infected with HB101-pagN strain at $37^{\circ} \mathrm{C}$ for $1 \mathrm{~h}$ (MOI 1:10). The percentage of internalized bacteria was calculated as described in Materials and Methods and related to values obtained for $\mathrm{CHO}$ cells, set at $100 \%$. Results represent mean values \pm SD obtained from three independent experiments. Results were compared using a Mann Whitney test $\left.{ }^{* * *} p<0.001,{ }^{* *} p<0.01\right)$ 
A

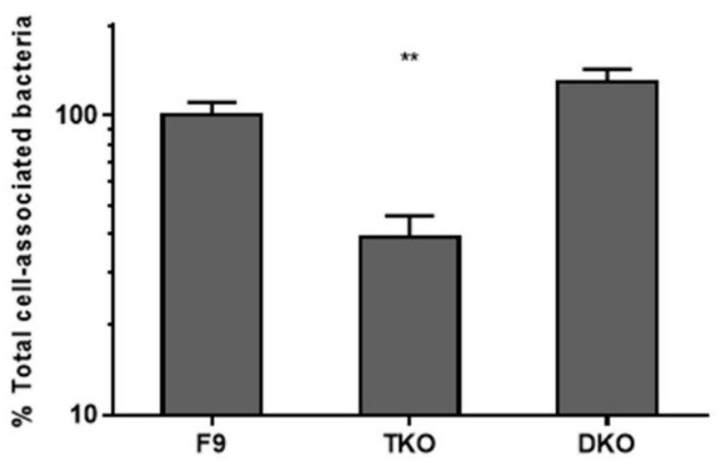

B

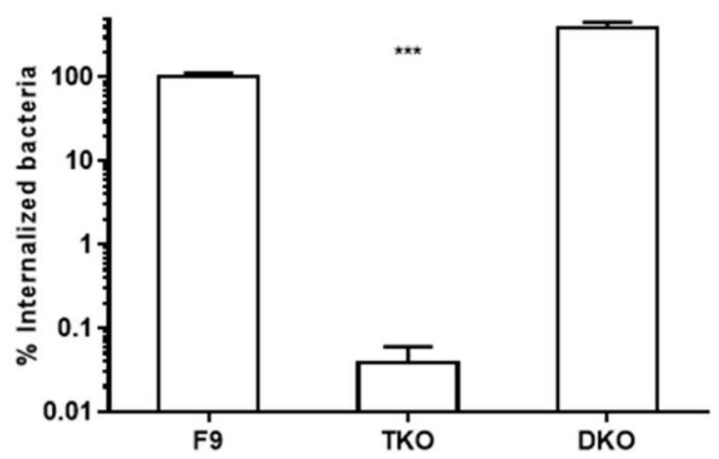

Fig. 4 The binding and invasiveness of Yersinia Invasin require $\beta 1$ integrin receptor. F9, triple knockout (TKO) and double knockout (DKO) cells were infected with MC-InvGFP strain at $\mathrm{MOI} 1: 10$ at $37^{\circ} \mathrm{C}$ for $1 \mathrm{~h}$. The percentage of total cell-associated (a) and intracellular (b) bacteria was determined as described in Materials and Methods. Obtained results are expressed relative to values obtained with F9 cells, set at $100 \%$. Results were compared using a Mann Whitney test $\left({ }^{* * *} p<0.001,{ }^{* *} p<0.01\right)$

\section{A}



C

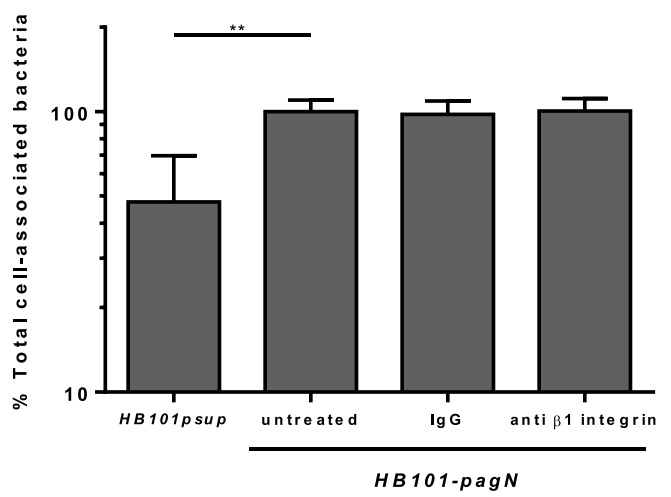

B

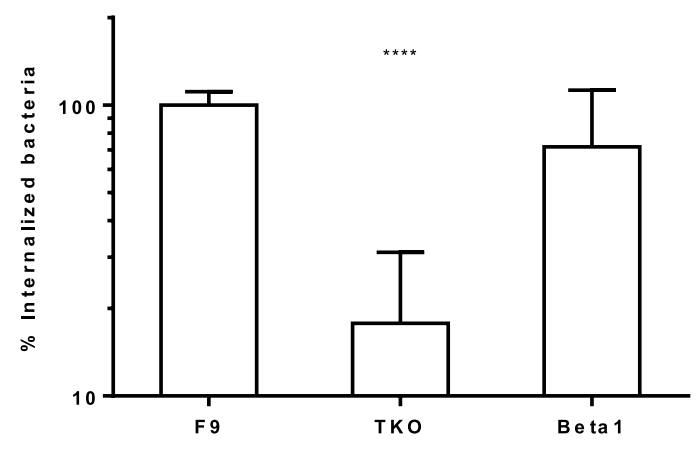

D



Fig. 5 HSPG and $\beta 1$ integrin cooperate to induce PagN-mediated internalization. a-b Parental F9, triple knockout (TKO) and double knockout (DKO) cells were infected with $\mathrm{HB101-pagN}$ at $\mathrm{MOI}$ 1:10 at $37^{\circ} \mathrm{C}$ for $1 \mathrm{~h}$. a Percentages of total cell-associated bacteria and (b) internalized bacteria were determined as described in the Materials and Methods. Results shown are expressed relative to values got with the parental F9 cells (F9), set at $100 \%$. c-d pgsA745 cells were untreated or treated with integrin $\beta 1$ blocking antibody and $\operatorname{lgG}$ at $50 \mu \mathrm{g} / \mathrm{mL}$ for 30 min at $4^{\circ} \mathrm{C}$ prior to the addition of HB101-pagN or HB101-psup at MOI 1:10 for $1 \mathrm{~h}$ at $37^{\circ} \mathrm{C}$. c Percentages of total cell-associated bacteria and (d) internalized bacteria were determined as described in the Materials and Methods. Results obtained are expressed relative to values obtained for untreated cells infected with HB101-pagN, arbitrarily set at 100\%. Results represent means \pm SD of three independent experiments with two infected wells per experiment. Results were compared using a Mann Whitney test $\left({ }^{* * *} p<0.0001,{ }^{* *} p<0.01\right)$ 
treated with a blocking anti- $\beta 1$-chain integrin antibody or with IgG as a control was measured. As shown in Fig. 5d, the pre-treatment with an anti- $\beta 1$ integrin antibody significantly reduced the percentage of internalized HB101-pagN to a level similar to that obtained with the HB101-psup strain. In addition, the number of internalized HB101-pagN obtained in cells untreated or treated with IgG was similar. The difference observed is not due to a difference in the ability of the bacteria to adhere to cells as the pre-treatment with either an anti- $\beta 1$-chain integrin antibody or IgG resulted in similar level of the total number of cellassociated bacteria (Fig. 5c). These data confirm that the internalization triggered by $\mathrm{PagN}$ depends on HSPG and $\beta 1$ integrin.

As $\mathrm{CHO}$ cells allowed a high level of PagN-mediated invasion, the following experiments aimed to characterize PagN-mediated internalization were performed only with this cell line.

\section{S. Typhimurium Rck- and PagN- mediated internalization hijacks the host cellular actin, leading to a zipper mechanism}

To demonstrate that PagN alone can induce cell adhesion, actin cytoskeletal rearrangement and cell invasion, a model with $2 \mu \mathrm{m}$ latex beads coated with PagN fused to Glutathione S-Transferase (PagN-beads) has been established and GST-coated beads were used as control. GST-PagN fusion protein was produced and purified from BL21 pLysS harboring pGEX4T2-PagN. Adhesion of PagN- and GST-coated beads to $\mathrm{CHO}$ cells was detected by their green autofluorescence and internalization of those beads by their double fluorescence due to labelled antibodies against GST and green autofluorescence (Table 1). Actin recruitment at the entry site was visualized using confocal microscopy. F-actin was stained with phalloidin conjugated to rhodamine (Fig. 6a) and coated beads were in green due to their green autofluorescence. Confocal images were generated and showed a local actin polymerization underneath PagNbeads (Fig. 6a). As expected, GST-coated beads were rarely found associated with cells as previously observed by Rosselin et al. (Table 1). As shown in Fig. 6a and Table 1, PagN is able to mediate adhesion, actin rearrangement and invasion into $\mathrm{CHO}$ cells. These data

Table 1 Abilities of latex beads coated with different GST fusion proteins to bind and mediate actin recruitment and internalization

\begin{tabular}{llll}
\hline Coated beads & Adhesion & Actin recruitment & Internalization \\
\hline GST & - & - & - \\
GST-113-159Rck & +++ & +++ & +++ \\
GST-PagN & +++ & +++ & +++ \\
\hline
\end{tabular}

(-): non-detectable; (+) low, (++) medium and (+++) high level show that PagN of $S$. Typhimurium induces adhesion and actin rearrangement, leading to bacterial invasion.

$S$. Typhimurium expresses two outer membrane proteins, PagN and Rck. Both induce actin polymerization, leading to bacterial internalization $[10,16]$. To compare the PagN-mediated invasion process with the mechanism induced by Rck of $S$. Typhimurium, we performed several experiments to confirm that Rck of $S$. Typhimurium had the same properties as Rck of $S$. Enteritidis [10, 12, 13]. Two models were used: (i) a non-invasive $E$. coli strain, which overexpressed Rck of $S$. Typhimurium (MC1061-rck) and its control E. coli strain, only harboring pSUP202 (MC1061-psup) and (ii) beads coated with the 114-159 peptide of Rck fused to Glutathione STransferase (Rck-beads) and its control GST-beads. The peptide 114-159 of $S$. Enteritidis Rck has been shown to be sufficient and necessary to induce adhesion, actin polymerization and internalization [10]. First, the adhesion and invasion level of MC1061-rck and MC1061psup were compared in Jeg3 cells, a cell line already shown to be permissive to Rck-mediated adhesion and invasion [10, 12]. As shown in Fig. 6b-c, MC1061-rck strain adhered to and invaded Jeg3 cells about 6 and 300 times more efficiently, respectively, than the control MC1061-psup strain did. Then, we confirmed that Rckbeads could induce cell adhesion, actin cytoskeletal rearrangement and cell invasion. As observed in Table 1 and Fig. 6a, Rck-beads are able to adhere and to induce host actin rearrangement or particle internalization. Taken together, our results show that bacteria expressing Rck, as well as beads coated with Rck are good models to characterize the internalization mechanism induced by Rck of $S$. Typhimurium and to compare it to the PagN-mediated invasion mechanism.

The interaction of HB101-pagN or the PagN-beads with $\mathrm{CHO}$ cell surface were further analyzed by scanning electron microscopy and compared to the membrane rearrangement observed with MC1061-Rck or Rck-beads incubated with Jeg3 cells. In Fig. 7, the different stages of PagN- (Fig. 7a-b) and Rck- (Fig. 7c-d) mediated invasion can be pictured, i.e. adherent bacteria or beads associated with cellular extension membrane, partially engulfed bacteria or beads with a membrane rearrangement and totally internalized beads. The PagN-dependent membrane rearrangements are weak and similar to the membrane engulfment observed during the Rck-mediated invasion. This suggests that PagN mediates a Zipper-like entry mechanism like the outer membrane protein Rck.

\section{The signaling pathway induced by $S$. Typhimurium Rck- and PagN-mediated internalization, involves the PI 3- kinase pathway}

The $\beta 1$ integrin and Rck of $S$. Enteritidis trigger a signaling cascade involving the class I PI 3-kinase p $85 \alpha$-p110 



Fig. 7 Rck and PagN of S. Typhimurium mediate a Zipper-like entry mechanism. a-b CHO cells were incubated with PagN-beads (a) or HB101-pagN (b). cd Jeg-3 cells were incubated with Rck-beads (c) or MC1061-rck (d). After $1 \mathrm{~h}$, the cells were washed and then processed for scanning electron microscopy 
heterodimer pathway $[12,32]$. To investigate the specificity of this signaling cascade with regard to the mechanism induced by PagN and Rck of $S$. Typhimurium, the effect of the p110 heterodimer inhibitor (AS-604850) on adhesion and entry of HB101-pagN and MC1061-rck was examined. Addition of AS-604850 to $\mathrm{CHO}$ and Jeg3 cell monolayers before adherence and invasion assays had no effect on adhesion as the number of associated HB101-pagN and MC1061-rck bacteria were similar that of DMSO-treated cells (Fig. 8a-c). However, the number of internalized Rck-expressing bacteria decreased in a dose-dependent manner with this inhibitor. Similar results were observed with PagNexpressing bacteria (Fig. 8b-d).

To obtain clear evidence that the class I PI 3-kinase p $85 \alpha-p 110$ is needed for the invasion mechanism induced by PagN and Rck of $S$. Typhimurium, the dominant negative form of $\mathrm{p} 85 \alpha(\Delta \mathrm{p} 85 \alpha)$ and the wild-type form of $\mathrm{p} 85 \alpha$ (Wp85 $\alpha$ ) were stably overexpressed in $\mathrm{CHO}$ and Jeg3 cells. Thirty-five amino acids from residues $479-513$ of $\mathrm{p} 85 \alpha$ are deleted in the dominant negative form, known to inhibit PI 3-kinase activation [12, 33]. The ability of HB101-pagN and MC1061-rck to bind to and invade these stably transfected cells was thus compared. As shown in Fig. 8e-h, the number of internalized bacteria expressing either PagN or Rck was significantly lower in $\Delta \mathrm{p} 85 \alpha$ cells, compared to that in Wp $85 \alpha$ cells, while no significant change was highlighted in the number of cell-associated bacteria between the transfected cell lines. These results indicate that the p85 $\alpha$-p110 heterodimer plays a role in the signaling pathway induced by both PagN and Rck, leading to bacterial internalization into cultured cells.

Activation of the PI 3-kinase requires the interaction of the SH2 domains of the p85 subunit with tyrosine phosphorylated proteins [34]. To assess the role of protein tyrosine kinases in $S$. Typhimurium PagN- or Rckmediated internalization, the effect of treatment with genistein, a specific inhibitor of protein tyrosine kinases, was analyzed on PagN or Rck-mediated adhesion and internalization. As shown in Fig. 9, the PagN- or Rckmediated invasion decreased in the presence of genistein in a dose-dependent manner, whereas no effect on PagN- or Rck-mediated adhesion was highlighted. These results show that the PagN- or Rck-dependent internalization mechanism requires tyrosine phosphorylation.

Taken together, these data demonstrate that like for Rck invasion, PagN of $S$. Typhimurium induces and






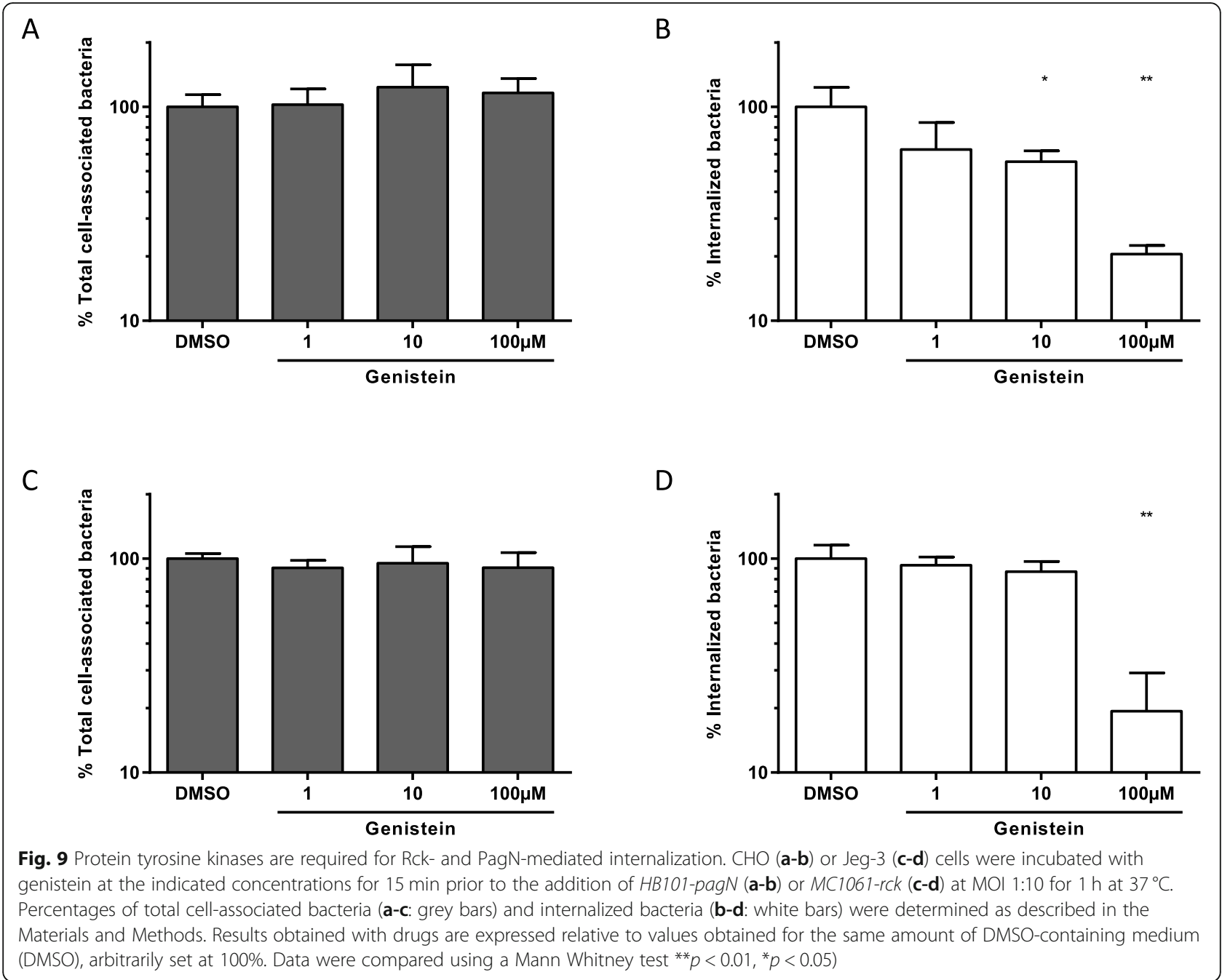

requires the PI 3-kinase signaling pathway to trigger bacterial internalization.

\section{Discussion}

S. Typhimurium takes advantage of different strategies to invade host cells. The major determinant of this invasiveness described in the literature is the T3SS-1, but other T3SS-independent mechanisms are also used by $S$. Typhimurium to gain entry into host cells such as the outer membrane proteins, Rck and PagN. Our study aimed to characterize better PagN and the entry pathway induced by this outer membrane protein. Previously, the presence of the pagN ORF was studied in few strains or genomes and this ORF was shown to be present in all the strains tested $[19,21,24]$. Based on Enterobase, we were able to confirm the presence of the pagN ORF on a very large dataset of more than 188,000 genomes of Salmonella, including genomes of the two Salmonella species, i.e. S. bongori and S. enterica, of all S. enterica subspecies and of 465 different serovars of $S$. enterica subsp. enterica. More than $99.6 \%$ of the tested genomes were positive for the gene, confirming studies based on a more limited number of strains/genomes. Moreover, for the first time, we highlighted some allelic specificity at the species, subspecies and serovar levels. Despite this allelic specificity, allelic variants show a very high conservation within $S$. enterica subsp. enterica, and also within other subspecies and species but to a lower extent. This high conservation does not, however, predict the functionality of the protein as it has recently been shown that only one substitution in loop 1 or 2 could be sufficient to increase the adhesive and invasive properties of PagN [35]. Further studies are required to decipher the amino acids/peptides important for PagN function, especially those in the predicted outer membrane loops.

Based on several lines of evidence, Lambert and Smith indicated that the epithelial cell surface receptor of PagN may be a HSPG [17]. They showed that $S$. Typhimurium and recombinant E. coli expressing 
PagN had a significant decrease in the ability to invade cells presenting under-glycosylated proteoglycans and that PagN-mediated internalization was significantly reduced in cells pre-treated with exogenous glycosaminoglycans and heparin. In our study, we compared the level of PagN-mediated invasion in different cell lines and identified them as permissive, resistant, and intermediate cells to this invasion process. However, the quantification of HS, which occurs as HSPG, on the surface of cells of these lines did not allow us to establish a link with the permeability/resistance of the cells to PagN-mediated invasion. Indeed, HT29 cells, which are extremely resistant to PagN-mediated invasion, express the highest amount of HS on their surface compared to the other cell lines tested. Therefore, the susceptibility/resistance to the PagN-mediated invasion is not proportional to the distribution of HS on these cell lines. As the PagN-mediated invasion is reduced in HSPG deficient cells compared to parental cells, all these results suggest that HSPG are necessary but not sufficient for $S$. Typhimurium internalization and thus could be considered as a co-receptor in PagN-mediated invasion.

The literature describes clearly that HSPG can be conjugated onto a variety of proteins to induce a signaling pathway, allowing the invagination of the cell membrane. Exosomes, cell penetrating peptides, viruses, bacteria, growth factors, lipoproteins and morphogens among other ligands penetrate cells through HSPG-mediated endocytosis. This leads to the modulation of biological activities of these molecules by influencing the duration and potency of the signaling. HSPG may thus act as a co-receptor for different cell surface receptors. The ligand-binding to HSPG results in conformational change of ligand, allowing it to present to endocytosis receptors with a high-affinity [36]. HSPG endocytosis seems thus not to be limited to one particular pathway, and changes depending on the type of extracellular ligand and cellular context. HSPG are exclusively produced by epithelial cells [37] and they have been detected in the intestine of humans [38] and mice [39]. Binding to host cells through recognition of HSPG has been associated with the invasion of several bacteria such as Neisseria gonorrhoeae [40]. Syndecan-1 and -4 are involved in attachment of host cells by Neisseria gonorrhoeae [41, 42], acting as co-receptor to facilitate bacterial internalization thanks to the $\beta 1$ integrin receptor [43]. Syndecan-1 is a highly conserved, multifunctional receptor and the major HSPG expressed on intestinal epithelial cell surfaces [44]. As Syndecan-1 and $\beta 1$ integrin generate a signal via the PI 3-kinase pathway [45] and undergo endocytosis upon clustering [46], our results reinforce the observation of Lambert and Smith
[17], suggesting that Syndecan-1 is involved in the PagN-mediated internalization mechanism.

Signaling molecules are differentially targeted by bacteria to promote invasion. During Zipper bacterial invasion, the receptor-ligand interaction leads to a PI 3kinase signaling pathway and the stimulation of actin cytoskeletal rearrangements, promoting the advance of pseudopods [47]. In this study, the signaling pathway induced by $S$. Typhimurium Rck and PagN, leading to bacterial internalization was characterized and compared to elucidate when the bacteria use these two outer membrane proteins. Using a pharmacological inhibitor and a dominant negative mutant of class I PI 3-kinase, we demonstrated in this study that the signaling transduction induced by $S$. Typhimurium Rck requires (p85p110) PI 3-kinase as Rck of $S$. Enteritidis. In addition, the use of these tools also allowed us to show that (p85p110) PI 3-kinase is required for the signaling transduction which leads to PagN-mediated invasion without affecting attachment.

As protein tyrosine kinase is an upstream signaling molecule of (p85-p110) PI 3-kinase during the Rckmediated internalization of $S$. Enteritidis, the involvement of protein tyrosine kinase in PagN- and Rckmediated invasion of $S$. Typhimurium was investigated. Our data highlighted that phosphorylation of tyrosine is required for the Rck- and PagN-mediated invasion by showing that the invasion level induced by Rck or PagN was significantly reduced in cells treated with the inhibitor genistein. Our data demonstrate that the signaling induced by Rck- and PagN-mediated entry of $S$. Typhimurium has similarities and involves the PI 3-kinase pathway, to allow bacterial internalization.

The scanning electron microscopy analysis of the interaction between either HB101-pagN or PagN-beads and epithelial host cell surface revealed a Zipper-like structure surrounding the adherent bacteria and coated beads. These data, combined with the fact that (i) $\beta 1$ integrin is required for PagN-mediated internalization and has been described in the literature as a receptor, allowing Zipper-like process and (ii) PagN alone mediates a PI 3-kinase signaling pathway, leading to internalization, strongly suggest that PagN and Rck of $S$. Typhimurium trigger cell invasion through a Zipperlike mechanism, as during Rck-mediated internalization of $S$. Enteritidis [10].

The transcription of $p a g N$ is directly regulated by PhoP/PhoQ [48]. This two-component system is activated by an acidified environment and a low $\mathrm{Mg}^{2+}$ concentration, conditions found intracellularly, inside the Salmonella-containing vacuole (SCV). By contrast, this environmental condition is not favorable for Rck production (data not shown). Currently, Rck production is known to be directly regulated by SdiA in an AHL- 
dependent manner $[8,49]$ despite the fact that some studies have shown that Salmonella does not produce AHLs and that some evidence suggests a lack of AHL signaling molecules in the mammalian intestine $[15,50]$. In addition, the genes encoding T3SS- 1 are induced extracellularly (by high osmolarity and low oxygen concentration) and downregulated after internalization [51, 52]. Altogether, these data show that $S$. Typhimurium expresses and uses its invasion factors under different environmental conditions, suggesting a specificity of the entry route by Salmonella strains which depends on the host cell environment.

In Salmonella pathogenicity, the importance of Rckand PagN-mediated invasion remains unknown. In vivo studies in mice suggest an intestinal role of PagN and Rck [15, 21, 23] and lead to several hypotheses. In the intestine, EGFR, HSPG and $\beta 1$ integrins are present on the surface of epithelial cells constituting the intestinal crypt base [53]. As Salmonella can target intestinal stem cells [54], Rckand PagN- mediated invasion could occur at the lumen site of the crypts. In addition, $M$ cells express $\beta 1$ integrins on their luminal side [55]. Salmonella is able to invade and destroy $\mathrm{M}$ cells, leading to invasion and colonization of the intestine [56]. As a Salmonella strain with a nonfunctional T3SS-1 is still able to invade $M$ cells in mouse intestine, it is possible that the PagN-mediated invasion may be targeting $M$ cells [57-59]. Moreover, EGFR, HSPG and $\beta 1$ integrins are found to be expressed on the basolateral membrane of villus enterocytes [60-62]. As Salmonella can cross the intestinal barrier and exit on the basolateral side [63,64], one hypothesis could be that Rck and PagN allow Salmonella invasion of enterocytes via the basolateral side. Based on the fact that Salmonella uses its T3SS-1 to alter epithelial cell polarity to allow bacterial invasion, another possibility thus could be that initial Salmonella invasion on the apical side induces a redistribution of HSPG, $\beta 1$ integrins and EGFR on the cell surface, allowing PagN- and Rck- mediated invasion from the apical side of epithelium [65].

Salmonella colonization is not limited to the intestinal tract. Indeed, Salmonella can disseminate and colonize systemic sites [66]. Considering that (i) a $S$. Typhimurium strain with a non fonctional T3SS-1 is still able to infect mice and colonize systemic organs such as the liver [67], (ii) Salmonella colonization of mice liver is significantly reduced in absence of PagN [21, 23], (iii) EGFR and $\beta 1$ integrins are expressed on the cell surface of hepatocytes $[68,69]$, another hypothesis could be that PagN- and Rck-mediated invasion allow the bacterial colonization of systemic organs such as the liver. The fact that Rck confers resistance to complement- mediated killing, reinforces this hypothesis [70]. The next step now is to investigate these different hypotheses using organoid models as a primary intestinal epithelium in vitro culture model.

\section{Conclusions}

Overall, the comparison of PagN- and Rck- mediated invasion of $S$. Typhimurium highly indicates that PagN induces a phosphatidylinositol 3-kinase signaling pathway, leading to a Zipper-like entry mechanism as the Salmonella outer membrane protein Rck. The investigation of the molecular elements of the signal transduction mediated by PagN supplies new comprehensions into T3SS-1-independent invasion mechanisms and could help to explain the specificity of each internalization process pathway.

\section{Methods}

\section{Bioinformatics analyses}

We retrieved the wgMLST profiles of 195,555 Salmonella strains recorded in Enterobase, an online platform that assembles draft genomes from Illumina short reads [71] on March 27, 2019. Among these strains, we kept only those presenting consistent serovar predictions (obtained using the online typing tool SISTR [72]). Consequently, the analysis was performed on 188,233 genomes. Allelic data at the pagN locus (referred to as STMMW_03171 in Enterobase's wgMLST scheme) were retrieved from the dataset and the distribution of the alleles was studied according to the Salmonella species, subspecies and serovars. The diversity among nucleotide sequences was calculated at each taxonomic level (species, subspecies and serovar) using Nei's haplotypic diversity (Hd), computed using the R-package pegas [73, 74]. After translation, sequences were aligned with the protein encoded by allele designated as No. 1 in Enterobase using ClustalW implemented in the software Geneious 10.2.2 (https://www.geneious.com).

\section{Cell lines and reagents}

Various mammalian cell lines were used in this study. Parental F9, and integrin $\beta 1$ double (DKO) and triple (TKO) knockout F9 embryonal carcinoma cell lines (kindly provided by Dr. C. Le Bouguenec, Institut Pasteur Paris, France) as well as Chinese Hamster Ovary (CHO) cells (ATCC: CCL-61) and HT29 cells, human caucasian colon adenocarcinoma cells (ATCC: HTB-38) were cultured in DMEM (Dulbecco's modified Eagle's medium, Gibco) containing glucose $25 \mathrm{mM}$ supplemented with FBS 10\% (fetal bovine serum; Sigma), Lglutamine $2 \mathrm{mM}$ (Gibco) in a humidified atmosphere at $37^{\circ} \mathrm{C}$ and $\mathrm{CO}_{2} 5 \%$. Jeg- 3 cells, human epithelial placental cells (ATCC: HTB-36), and the stably transfected cells, Jeg-3 Wp $85 \alpha$ and $\triangle \mathrm{p} 85 \alpha$, were grown in MEM medium 
containing Glutamax (Gibco), FBS 10\%, non-essential amino acids $1 \mathrm{mM}$ and sodium pyruvate $1 \mathrm{mM}$ (Gibco) [12]. Caco-2 cells (ATCC: HTB-37) are human colonic epithelial cell lines cultured in DMEM supplemented with FBS 20\%, nonessential amino acids $1 \mathrm{mM}$, sodium pyruvate $1 \mathrm{mM}$ and L-glutamine $2 \mathrm{mM}$. pgsA745 cells (ATCC: CRL-2242) referred to as $\Delta X y l T$ [75] were routinely cultured in F-12 K medium (Kaighn's Modification of Ham's F-12 medium; ATCC) supplemented with FBS $10 \%$.

All inhibitors were dissolved in DMSO (dimethyl sulfoxide, Sigma) at the following stock concentration: AS604850 (Sigma at $35 \mathrm{mM}$ ); Genistein (Calbiochem at $100 \mathrm{mM}$ ). In drug-treated cells, the maximum final concentration of DMSO never exceeded 0.1\% (v/v).

\section{Bacterial strains and growth conditions}

In Table 2, the bacterial strains used in this study are listed. Bacteria were routinely cultured in LB (Luria-Bertani) broth overnight with shaking at $150 \mathrm{rpm}$ at $37^{\circ} \mathrm{C}$ with the corresponding antibiotic: tetracyclin (Tc, Sigma) $12.5 \mu \mathrm{g} / \mathrm{ml}$, chloramphenicol (Cm, Sigma) $34 \mu \mathrm{g} /$ $\mathrm{ml}$ and carbenicillin (Cb, Sigma) $100 \mu \mathrm{g} / \mathrm{ml}$.

\section{Expression of Wp85a and mutant $\Delta \mathrm{p} 85 \mathrm{a}$ in $\mathrm{CHO}$ cells}

$\mathrm{CHO}$ cells stably overexpressing Wp85 $\alpha$ or $\Delta \mathrm{p} 85 \alpha$ were obtained as described by Mijouin et al. [12]. Selection was started by adding G-418 at $1 \mathrm{mg} / \mathrm{ml}$ to the cell culture medium. For pcDNA3.1 and Rev. pcDNA3.1 primers (listed in Table 3) were used to screen by polymerase chain reaction (PCR) the resistant $\mathrm{CHO}$ cells expressing each protein. Proliferation of Wp85 $\alpha$ and mutant $\Delta \mathrm{p} 85 \alpha \mathrm{CHO}$ cells was similar as described previously [12].

\section{DNA constructs}

The $\operatorname{pagN}$ gene was amplified from wild-type $S$. Typhimurium 14028 strain by PCR (polymerase chain reaction) using pagN EcoRI forw primer (flanked by EcoRI restriction site) and pagN NcoI rev primer (flanked by NcoI restriction site) and cloned into pSUP202 expression vector [77], before being transformed into $E$. coli HB101. The same method was used to construct the $(\mathrm{His})_{6}-\mathrm{pagN}$ without its signal peptide (PagN-GST) into pGEX-4 T-2 expression vector (Amersham-Pharmacia), using primers pagN-GST forw and pagN-GST rev, flanked by BamHI and EcoRI restriction sites, before being transformed into E. coli BL21 pLysS. In Table 3, primer sequences used in this study are listed.

\section{Adhesion and invasion assays}

Cells were cultured in 24-well tissue culture plates (Falcon) to obtain a confluent monolayer. They were infected for $60 \mathrm{~min}$ at $37^{\circ} \mathrm{C}$ with bacteria in DMEM without FBS.

For adhesion assays, after infection, cells were washed at least four times with PBS (phosphate buffer saline, Sigma) and then lysed at $4{ }^{\circ} \mathrm{C}$ with distilled water. Viable bacteria (extra- and intra-cellular) were counted after plating serial dilutions on TSA (Tryptic Soy Agar).

Table 2 Bacterial strains and plasmids used in this study

\begin{tabular}{|c|c|c|}
\hline Strain or Plasmid & Relevant characteristeristics & Source or reference \\
\hline \multicolumn{3}{|l|}{ Strains } \\
\hline HB101 & $\begin{array}{l}\text { Noninvasive laboratory strain (supE44 hsdS2O }\left(\mathrm{r}_{\mathrm{B}}{ }^{-} \mathrm{m}_{\mathrm{B}}{ }^{-} \text {) recA13 ara-14 proA2 lacY1 galk2 }\right. \\
\text { rpsL20 xyl-5 mtl-1 leuB6 thi-1) }\end{array}$ & Promega \\
\hline BL21 pLysS & $\begin{array}{l}\text { An E. coli strain which is lysogenic for } \lambda \text {-DE3 and contains the T7 bacteriophage gene I, } \\
\text { encoding T7 RNA polymerase under the control of the lac UV5 promoter as well as a } \\
\left.\text { plasmid, pLysS, which carries the gene encoding T7 lysozyme (Cm }{ }^{r}\right)\end{array}$ & Promega \\
\hline MC1061 & E. coli hsdR mcrB araD139 $\Delta$ (araABC-leu)7679 $\Delta$ lacX74 galU galK rpsL thi & {$[76]$} \\
\hline \multicolumn{3}{|l|}{ Plasmids } \\
\hline pSUP202 & pMB1 replicon $\left(\mathrm{Cb}^{r}, \mathrm{Tc}^{\mathrm{r}}, \mathrm{Cm}^{r}\right)$ & {$[77]$} \\
\hline pSUP202-Rck & Vector carrying the $r c k$ gene $\left(\mathrm{Cb}^{r}, \mathrm{Cm}^{r}\right)$ & {$[14]$} \\
\hline pSUP202-PagN & Vector carrying the pagN gene $\left(\mathrm{Cb}^{r}, \mathrm{Cm}^{r}\right)$ & This study \\
\hline pSUP202-Inv GFP & Vector carrying the invasin gene from Yersinia enterocolitica and gfp gene $\left(\mathrm{Cb}^{r}\right)$ & {$[14]$} \\
\hline $\mathrm{pGEX}-4 \mathrm{~T}-2$ & Fusion vector carrying the glutathione S-transferase gene $\left(\mathrm{Cb}^{r}\right)$ & GE Healthcare \\
\hline pGEX-4T-2114-159 Rck & Vector carrying the glutathione S-transferase (GST) gene linked to 113-159 rck gene (Cbr) & {$[10]$} \\
\hline pGEX-4 T-2 PagN & Vector carrying the glutathione S-transferase (GST) gene linked to pagN gene $\left(\mathrm{Cb}^{r}\right)$ & This study \\
\hline pcDNA 3.1 Wp85 & Vector carrying the wild-type bovine $p 85 a$ sequence $\left(\mathrm{Cb}^{r}\right)$ & {$[12]$} \\
\hline pcDNA $3.1 \triangle$ p85 & Vector carrying the mutant bovine p85a sequence $\left(\mathrm{Cb}^{r}\right)$ & {$[12]$} \\
\hline
\end{tabular}

$\mathrm{Cb}^{r}$ carbenicillin resistance, $T c^{r}$ tetracyclin resistance, $\mathrm{Cm}^{r}$ chloramphenicol resistance 
Table 3 Primers used in this study

\begin{tabular}{ll}
\hline Primer name & Sequence $\mathbf{( 5}$ ' to $\mathbf{3}$ ') \\
\hline pagN ECORl forw & CTC GAA TTC ATT AAG GCA GGT TCT GAA ATG \\
pagN Ncol rev & TCT CCA TGG TTA AAA GGC GTA AGT AAT GCC \\
pagN-GST forw & CTC GGA TCC CAT CAT CAT CAT CAT CAT AAA GAA GGG ATC TAT ATC ACC GGG A \\
pagN-GST rev & TCT GAA TTC TTA AAA GGC GTA AGT AAT GCC GAG \\
Forw pCDNA3.1 & GAC TCA CTA TAG GGA GAC CCA AGC TGG CTA \\
Rev pCDNA3.1 & GCT GGG CAA CTA GAA GGC ACA GTC GAG GCT \\
\hline
\end{tabular}

The number of internalized bacteria was determined using a gentamicin protection assay to kill extracellular bacteria, as previously described [11]. After $90 \mathrm{~min}$ treatment with gentamicin at $100 \mu \mathrm{g} / \mathrm{ml}$ (Gibco), cells were washed and lysed in cold distilled water. The number of internalized bacteria was enumerated as before [11].

\section{Flow cytometry}

The CHO, pgsA745, HT29 and Caco2 cells were fixed for $15 \mathrm{~min}$ in PFA 2\% (paraformaldehyde) at $4{ }^{\circ} \mathrm{C}$ and then washed with cold wash buffer containing BSA at $0.5 \%$ (bovine serum albumin). Cell samples were saturated with PBS containing BSA $2.5 \%$ at $4{ }^{\circ} \mathrm{C}$ for $15 \mathrm{~min}$. The mouse anti-heparin/heparan sulfate (HS; clone T320.11, Millipore) was diluted to 1:40 in PBS containing BSA $1 \%$ and incubated with cells for $45 \mathrm{~min}$ on ice and then washed three times. As secondary antibody, Alexa 488-conjugated goat anti-mouse antibodies (Invitrogen) diluted to $1: 200$ in PBS containing BSA 1\% were used and incubated with cells for $45 \mathrm{~min}$ on ice. After three washes, cells were resuspended in PFA $2 \%$ and then the relative fluorescence of the cell lines was analyzed using a LSR-Fortessa X-20 analyzer (BD Biosciences). The relative surface expression of HS on cells is expressed as the percentage of positive cells (determined by Overton subtraction of isotype control histograms from labelled histograms [78]).

\section{Expression and purification of recombinant protein}

Recombinant GST-tagged PagN and 114-159 Rck proteins were induced in $E$. coli BL21 pLysS transformed with pGEX4T2-PagN or pGEX4T2-114-159 Rck upon treatment with IPTG $1 \mathrm{mM}$ (isopropyl $\beta$-D1-thiogalactopyranoside, Sigma) for $4 \mathrm{~h}$ as previously described [10]. For protein purification, cells were harvested by centrifugation, resuspended in buffer containing Tris pH $850 \mathrm{mM}$, EDTA $40 \mathrm{mM}$, sucrose $25 \%, \mathrm{MgCl}_{2} 100 \mathrm{mM}$, Triton X-100 0.2\%, PMSF (phenylmethylsulfonylfluoride) $1 \mathrm{mM}$ and cOmplete Protease Inhibitor Cocktail (Boehringer) and sonicated. After clearing, fusion proteins were affinity-purified from the soluble fraction on Glutathione-Sepharose
$4 \mathrm{~B}$ beads (Amersham Biosciences) following the manufacturer's instructions [10].

\section{Coating of latex beads}

$2 \mu \mathrm{m}$ diameter latex beads (polystyrene sulphate modified, Sigma) were washed and resuspended in PBS containg purified GST-114-159 Rck, GST-PagN and GST proteins. Proteins were adsorbed onto the beads at room temperature for $3 \mathrm{~h}$. After adding BSA $(20 \mathrm{mg} / \mathrm{ml})$, the beads were incubated for a further hour at room temperature. The beads were then washed in PBS.

\section{Immunofluorescence microscopy}

Jeg-3 and $\mathrm{CHO}$ cells on coverslips were infected with either GST-114-159 Rck-, GST-PagN- or GST- coated beads at MOI 50:1. After incubation for $30 \mathrm{~min}$, cells were washed in PBS to remove unbound extracellular beads. In brief, after fixation of the monolayers in PFA 4\%, and permeabilization in triton $0.2 \%$, actin was stained with Rhodamin-Phalloidin (diluted 1:200; Sigma;). Finally, coverslips were mounted in fluorescence mounting medium (Dako) and analyzed with a Leica SP8 confocal laserscanning microscope (Leica TCS SP8, Germany).

\section{Scanning Electron microscopy}

$\mathrm{CHO}$ and Jeg3 cells were grown on coverslips and infected with beads or bacteria to a cell ratio of 100:1. After 30 min of bacteria- or beads- cell contact at $37^{\circ} \mathrm{C}$, cells were washed in PBS and fixed in a mixture of PFA $4 \%$ and glutaraldehyde $1 \%(0.3 \mathrm{M} \mathrm{pH} 7.4)$ for $1 \mathrm{~h}$. Samples were then treated for scanning electron microscopy analysis as described in Burlaud-Gaillart et al. [79]. The observations were performed using a Zeiss Ultra plus FEG-SEM scanning electron microscope (Oberkochen, Germany).

\section{Statistical analysis}

Data were analyzed using an unpaired t test or a Mann Whitney test using Prism (version 6.0; GraphPad Software, La Jolla, CA, USA).

\section{Abbreviations}

AHL: N-acyl-L homoserine lactones; BSA: Bovine serum albumine; Cb: Carbenicillin; Cm: Chloramphenicol; DKO: Integrin $\beta 1$ double knockout; DMEM: Dulbecco's modified Eagle's medium; DMSO: Dimethyl sulfoxide; 
EGFR: Epidermal growth factor receptor; FBS: Fetal bovine serum; GST: Glutathione S-Transferase; Hd: Haplotype diversity; HS: Heparan sulphates; HSPG: Heparan sulfate proteoglycan; IPTG: Isopropyl $\beta-D-1-t h i o-$ galactopyranoside; LB: Luria-Bertani; MOI: Multiplicity of infection; PAF: Paraformaldehyde; PagN: phoP-activated gene; PBS: Phosphate buffer saline; PCR: Polymerase chain reaction; PI 3-kinase: Phosphatidylinositol 3kinase; PMSF: Phenylmethylsulfonylfluoride; Rck: Resistance to complement killing; R: Richness; SCV: Salmonella-containing vacuole; SPI-1: Salmonella pathogenicity island-1; Tc: Tetracyclin; TKO: Integrin $\beta 1$ triple knockout; T3SS1: Type III secretion system-1; TSA: Tryptic soy agar

\section{Acknowledgements}

The authors thank Dr. C. C. Le Bouguenec, Institut Pasteur Paris, France for donating F9, TKO and DKO cells and Y. Le Vern for flow cytometry expertise.

\section{Authors' contributions}

AW designed the research; EB, MV, MK, JBG and AW performed research; FK contributed analytic tools; AW, MV, MK, FK, OG, IVP and EB analyzed data; AW wrote the manuscript; PV provided critical comments. All the authors read and approved the final manuscript.

\section{Funding}

This work was supported by the ERA-NET InfectERA (SalHostTrop, ANR-15IFEC-0003).

\section{Availability of data and materials}

The datasets used to produce the results in Fig. 1 are publically available in Enterobase (https://enterobase.warwick.ac.uk/species/index/senterica). The analysis is available from Olivier Grépinet (olivier.grepinet@inrae.fr).

\section{Declarations}

\section{Ethics approval and consent to participate}

Not applicable.

\section{Consent for publication}

All the authors read and approved the final manuscript.

\section{Competing interests}

The authors declare that they have no competing interests.

\section{Author details}

${ }^{1}$ INRAE, Université de Tours, ISP, F-37380 Nouzilly, France. ${ }^{2}$ Present Address: Service Biologie Vétérinaire et Santé Animale, Inovalys, Angers, France. ${ }^{3}$ Plateforme IBiSA de Microscopie Electronique, Université de Tours et CHRU de Tours, Tours, France. ${ }^{4}$ Present Address: IRSD - Institut de Recherche en Santé Digestive, Université de Toulouse, INSERM, INRAE, ENVT, UPS, Toulouse, France.

\section{Received: 18 January 2021 Accepted: 29 March 2021}

\section{Published online: 21 May 2021}

\section{References}

1. Guibourdenche M, Roggentin P, Mikoleit M, Fields PI, Bockemuhl J, Grimont PA, et al. Supplement 2003-2007 (no. 47) to the white-Kauffmann-Le minor scheme. Res Microbiol. 2010;161(1):26-9. https://doi.org/10.1016/j.resmic.2 009.10 .002$.

2. Velge P, Wiedemann A, Rosselin M, Abed N, Boumart Z, Chausse AM, et al. Multiplicity of Salmonella entry mechanisms, a new paradigm for Salmonella pathogenesis. Microbiol Open. 2012;1(3):243-58. https://doi. org/10.1002/mbo3.28.

3. McClelland M, Sanderson KE, Spieth J, Clifton SW, Latreille P, Courtney L, et al. Complete genome sequence of Salmonella enterica serovar Typhimurium LT2. Nature. 2001;413(6858):852-6. https://doi.org/10.1038/35101614.

4. Hume PJ, Singh V, Davidson AC, Koronakis V. Swiss army pathogen: the Salmonella entry toolkit. Front Cell Infect Microbiol. 2017;7:348. https://doi. org/10.3389/fcimb.2017.00348.

5. Lou L, Zhang P, Piao R, Wang Y. Salmonella Pathogenicity Island 1 (SPI-1) and its complex regulatory network. Front Cell Infect Microbiol. 2019;9:270. https://doi.org/10.3389/fcimb.2019.00270.
6. Mambu J, Virlogeux-Payant I, Holbert S, Grepinet O, Velge P, Wiedemann A. An updated view on the Rck invasin of Salmonella: still much to discover. Front Cell Infect Microbiol. 2017;7:500. https://doi.org/10.3389/fcimb.2017.00500.

7. Ahmer BM, van Reeuwijk J, Timmers CD, Valentine PJ, Heffron F. Salmonella typhimurium encodes an SdiA homolog, a putative quorum sensor of the LuxR family, that regulates genes on the virulence plasmid. J Bacteriol. 1998;180(5):1185-93. https://doi.org/10.1128/JB.180. 5.1185-1193.1998.

8. Abed N, Grepinet O, Canepa S, Hurtado-Escobar GA, Guichard N, Wiedemann $A$, et al. Direct regulation of the pefl-srgC operon encoding the Rck invasin by the quorum-sensing regulator SdiA in Salmonella Typhimurium. Mol Microbiol. 2014;94(2):254-71. https://doi.org/10.1111/mmi.12738.

9. Erickson DL, Nsereko VL, Morgavi DP, Selinger LB, Rode LM, Beauchemin KA. Evidence of quorum sensing in the rumen ecosystem: detection of $\mathrm{N}$-acyl homoserine lactone autoinducers in ruminal contents. Can J Microbiol. 2002;48(4):374-8. https://doi.org/10.1139/w02-022.

10. Rosselin M, Virlogeux-Payant I, Roy C, Bottreau E, Sizaret PY, Mijouin L, et al. Rck of Salmonella enterica, subspecies enterica serovar Enteritidis, mediates zipper-like internalization. Cell Res. 2010;20(6):647-64. https://doi.org/10.103 8/cr.2010.45.

11. Wiedemann A, Mijouin L, Ayoub MA, Barilleau E, Canepa S, Teixeira-Gomes $A P$, et al. Identification of the epidermal growth factor receptor as the receptor for Salmonella Rck-dependent invasion. FASEB J. 2016;30(12):418091. https://doi.org/10.1096/fj.201600701R.

12. Mijouin L, Rosselin M, Bottreau E, Pizarro-Cerda J, Cossart P, Velge P, et al. Salmonella enteritidis Rck-mediated invasion requires activation of Rac1, which is dependent on the class I PI 3-kinases-Akt signaling pathway. FASEB J. 2012;26(4):1569-81. https://doi.org/10.1096/fj.11-189647.

13. Wiedemann A, Rosselin M, Mijouin L, Bottreau E, Velge P. Involvement of CSrc tyrosine kinase upstream of class I phosphatidylinositol (PI) 3-kinases in Salmonella Enteritidis Rck protein-mediated invasion. J Biol Chem. 2012; 287(37):31148-54. https://doi.org/10.1074/jbc.M112.392134.

14. Mambu J, Barilleau E, Fragnet-Trapp L, Le Vern Y, Olivier M, Sadrin G, et al. Rck of Salmonella Typhimurium delays the host cell cycle to facilitate bacterial invasion. Front Cell Infect Microbiol. 2020;10:586934. https://doi. org/10.3389/fcimb.2020.586934.

15. Dyszel JL, Smith JN, Lucas DE, Soares JA, Swearingen MC, Vross MA, et al. Salmonella enterica serovar Typhimurium can detect acyl homoserine lactone production by in mice. J Bacteriol. 2010;192(1):29-37. https://doi. org/10.1128/JB.01139-09.

16. Lambert MA, Smith SG. The PagN protein of Salmonella enterica serovar Typhimurium is an adhesin and invasin. BMC Microbiol. 2008;8(1):142. https://doi.org/10.1186/1471-2180-8-142.

17. Lambert MA, Smith SG. The PagN protein mediates invasion via interaction with proteoglycan. FEMS Microbiol Lett. 2009;297(2):209-16. https://doi. org/10.1111/j.1574-6968.2009.01666.x.

18. Belden WJ, Miller SI. Further characterization of the PhoP regulon: identification of new PhoP-activated virulence loci. Infect Immun. 1994; 62(11):5095-101. https://doi.org/10.1128/IAl.62.11.5095-5101.1994.

19. Folkesson A, Advani A, Sukupolvi S, Pfeifer JD, Normark S, Lofdahl S. Multiple insertions of fimbrial operons correlate with the evolution of Salmonella serovars responsible for human disease. Mol Microbiol. 1999; 33(3):612-22. https://doi.org/10.1046/j.1365-2958.1999.01508.x.

20. Rakov AV, Mastriani E, Liu SL, Schifferli DM. Association of Salmonella virulence factor alleles with intestinal and invasive serovars. BMC Genomics. 2019;20(1):429. https://doi.org/10.1186/s12864-019-5809-8.

21. Yang $Y$, Wan $C, X u H$, Aguilar ZP, Tan Q, Xu F, et al. Identification of an outer membrane protein of Salmonella enterica serovar Typhimurium as a potential vaccine candidate for salmonellosis in mice. Microbes Infect. 2013; 15(5):388-98. https://doi.org/10.1016/j.micinf.2013.02.005.

22. Kato A, Groisman EA, Howard Hughes Medical I. The PhoQ/PhoP regulatory network of Salmonella enterica. Adv Exp Med Biol. 2008;631:7-21. https:// doi.org/10.1007/978-0-387-78885-2_2.

23. Conner CP, Heithoff DM, Mahan MJ. In vivo gene expression: contributions to infection, virulence, and pathogenesis. Curr Top Microbiol Immunol. 1998;225:1-12. https://doi.org/10.1007/978-3-642-80451-9_1.

24. Suez J, Porwollik S, Dagan A, Marzel A, Schorr YI, Desai PT, et al. Virulence gene profiling and pathogenicity characterization of non-typhoidal Salmonella accounted for invasive disease in humans. PLoS One. 2013;8(3): e58449. https://doi.org/10.1371/journal.pone.0058449. 
25. EFSA. The European Union summary report on trends and sources of zoonoses, zoonotic agents and food-borne outbreaks in 2017. EFSA J. 2018;16(12):5500.

26. Annaval T, Wild R, Cretinon Y, Sadir R, Vives RR, Lortat-Jacob H. Heparan sulfate proteoglycans biosynthesis and post synthesis mechanisms combine few enzymes and few core proteins to generate extensive structural and functional diversity. Molecules. 2020;25(18):4215.

27. Finlay BB, Falkow S. Salmonella interactions with polarized human intestinal Caco-2 epithelial cells. J Infect Dis. 1990;162(5):1096-106. https://doi.org/10.1 093/infdis/162.5.1096.

28. Montgomery AM, Becker JC, Siu CH, Lemmon VP, Cheresh DA, Pancook JD, et al. Human neural cell adhesion molecule L1 and rat homologue NILE are ligands for integrin $a \beta_{3}$. J Cell Biol. 1996;132(3):475-85. https://doi.org/10.1 083/jcb.132.3.475.

29. Schlessinger J, Lax I, Lemmon M. Regulation of growth factor activation by proteoglycans: what is the role of the low affinity receptors? Cell. 1995;83(3): 357-60. https://doi.org/10.1016/0092-8674(95)90112-4.

30. Stephens LE, Sonne JE, Fitzgerald ML, Damsky CH. Targeted deletion of $\beta_{1}$ integrins in F9 embryonal carcinoma cells affects morphological differentiation but not tissue-specific gene expression. J Cell Biol. 1993;123(6 Pt 1):1607-20. https://doi.org/10.1083/jcb.123.6.1607.

31. Isberg RR, Leong JM. Multiple beta 1 chain integrins are receptors for invasin, a protein that promotes bacterial penetration into mammalian cells. Cell. 1990;60(5):861-71. https://doi.org/10.1016/0092-8674(90)90099-Z.

32. Pellinen T, Ivaska J. Integrin traffic. J Cell Sci. 2006;119(Pt 18):3723-31. https://doi.org/10.1242/jcs.03216.

33. Hara K, Yonezawa K, Sakaue H, Ando A, Kotani K, Kitamura T, et al. 1phosphatidylinositol 3-kinase activity is required for insulin-stimulated glucose transport but not for RAS activation in $\mathrm{CHO}$ cells. Proc Natl Acad Sci U S A. 1994;91(16):7415-9. https://doi.org/10.1073/pnas.91.16.7415.

34. Cantley LC. The phosphoinositide 3-kinase pathway. Science. 2002; 296(5573):1655-7. https://doi.org/10.1126/science.296.5573.1655.

35. Wu Y, Hu Q, Dehinwal R, Rakov AV, Grams N, Clemens EC, et al. The Not so Good, the Bad and the Ugly: Differential bacterial adhesion and invasion mediated by Salmonella PagN allelic variants. Microorganisms. 2020;8(4):489.

36. Christianson HC, Belting M. Heparan sulfate proteoglycan as a cell-surface endocytosis receptor. Matrix Biol. 2014;35:51-5. https://doi.org/10.1016/j.ma tbio.2013.10.004.

37. Simon-Assmann P, Bouziges F, Vigny M, Kedinger M. Origin and deposition of basement membrane heparan sulfate proteoglycan in the developing intestine. J Cell Biol. 1989;109(4 Pt 1):1837-48. https://doi.org/10.1083/jcb.109.4.1837.

38. Oshiro M, Ono K, Suzuki Y, Ota H, Katsuyama T, Mori N. Immunohistochemical localization of heparan sulfate proteoglycan in human gastrointestinal tract. Histochem Cell Biol. 2001;115(5):373-80. https://doi.org/10.1007/s004180100271.

39. Bode L, Salvestrini C, Park PW, Li JP, Esko JD, Yamaguchi Y, et al. Heparan sulfate and syndecan-1 are essential in maintaining murine and human intestinal epithelial barrier function. J Clin Invest. 2008;118(1):229-38. https:// doi.org/10.1172/JCI32335

40. van Putten JP, Paul SM. Binding of syndecan-like cell surface proteoglycan receptors is required for Neisseria gonorrhoeae entry into human mucosal cells. EMBO J. 1995;14(10):2144-54. https://doi.org/10.1002/j.1460-2075.1995.tb07208.x.

41. Alvarez-Dominguez C, Vazquez-Boland JA, Carrasco-Marin E, Lopez-Mato P, Leyva-Cobian F. Host cell heparan sulfate proteoglycans mediate attachment and entry of Listeria monocytogenes, and the listerial surface protein ActA is involved in heparan sulfate receptor recognition. Infect Immun. 1997;65(1):78-88. https://doi.org/10.1128/IAl.65.1.78-88.1997.

42. Freissler E, Meyer Auf der Heyde A, David G, Meyer TF, Dehio C. Syndecan-1 and syndecan-4 can mediate the invasion of Opa ${ }_{H S P G}$-expressing Neisseria gonorrhoeae into epithelial cells. Cell Microbiol. 2000;2(1):69-82. https://doi. org/10.1046/j.1462-5822.2000.00036.x

43. van Putten JP, Duensing TD, Cole RL. Entry of OpaA+ gonococci into HEp-2 cells requires concerted action of glycosaminoglycans, fibronectin and integrin receptors. Mol Microbiol. 1998;29(1):369-79. https://doi.org/10.1046/ j.1365-2958.1998.00951.x.

44. Gondelaud F, Ricard-Blum S. Structures and interactions of syndecans. FEBS J. 2019;286(15):2994-3007. https://doi.org/10.1111/febs.14828.

45. Yongchaitrakul T, Manokawinchoke J, Pavasant P. Osteoprotegerin induces osteopontin via syndecan-1 and phosphoinositol 3-kinase/Akt in human periodontal ligament cells. J Periodontal Res. 2009;44(6):776-83. https://doi. org/10.1111/j.1600-0765.2008.01190.x

46. Chen K, Williams KJ. Molecular mediators for raft-dependent endocytosis of syndecan-1, a highly conserved, multifunctional receptor. J Biol Chem. 2013; 288(20):13988-99. https://doi.org/10.1074/jbc.M112.444737.

47. Cossart $\mathrm{P}$, Sansonetti PJ. Bacterial invasion: the paradigms of enteroinvasive pathogens. Science. 2004;304(5668):242-8. https://doi.org/10.1126/science.1 090124

48. Gunn JS, Belden WJ, Miller SI. Identification of PhoP-PhoQ activated genes within a duplicated region of the Salmonella typhimurium chromosome. Microb Pathog. 1998;25(2):77-90. https://doi.org/10.1006/mpat.1998.0217.

49. Smith JN, Ahmer BM. Detection of other microbial species by Salmonella: expression of the SdiA regulon. J Bacteriol. 2003;185(4):1357-66. https://doi. org/10.1128/JB.185.4.1357-1366.2003.

50. Swearingen MC, Sabag-Daigle A, Ahmer BM. Are there acyl-homoserine lactones within mammalian intestines? J Bacteriol. 2013;195(2):173-9. https://doi.org/10.1128/JB.01341-12.

51. Boddicker JD, Jones BD. Lon protease activity causes down-regulation of Salmonella pathogenicity island 1 invasion gene expression after infection of epithelial cells. Infect Immun. 2004;72(4):2002-13. https://doi.org/10.1128/ |Al.72.4.2002-2013.2004.

52. Ibarra JA, Knodler LA, Sturdevant DE, Virtaneva K, Carmody AB, Fischer ER, et al. Induction of Salmonella pathogenicity island 1 under different growth conditions can affect Salmonella-host cell interactions in vitro. Microbiology. 2010;156(Pt 4):1120-33.

53. Meran L, Baulies A, Li VSW. Intestinal stem cell niche: the extracellular matrix and cellular components. Stem Cells Int. 2017;2017:7970385.

54. Liu X, Lu R, Wu S, Sun J. Salmonella regulation of intestinal stem cells through the Wnt/beta-catenin pathway. FEBS Lett. 2010;584(5):911-6. https://doi.org/10.1016/j.febslet.2010.01.024.

55. Clark MA, Hirst BH, Jepson MA. M-cell surface beta1 integrin expression and invasin-mediated targeting of Yersinia pseudotuberculosis to mouse Peyer's patch M cells. Infect Immun. 1998;66(3):1237-43. https://doi.org/10.1128/IAI. 66.3.1237-1243.1998.

56. Jones BD, Ghori N, Falkow S. Salmonella typhimurium initiates murine infection by penetrating and destroying the specialized epithelial M cells of the Peyer's patches. J Exp Med. 1994;180(1):15-23. https://doi.org/10.1084/ jem.180.1.15.

57. Clark MA, Reed KA, Lodge J, Stephen J, Hirst BH, Jepson MA. Invasion of murine intestinal M cells by Salmonella typhimurium inv mutants severely deficient for invasion of cultured cells. Infect Immun. 1996;64(10):4363-8. https://doi.org/10.1128/IAl.64.10.4363-4368.1996.

58. Jensen VB, Harty JT, Jones BD. Interactions of the invasive pathogens Salmonella typhimurium, Listeria monocytogenes, and Shigella flexneri with M cells and murine Peyer's patches. Infect Immun. 1998;66(8):3758-66. https://doi.org/10.1128/IAl.66.8.3758-3766.1998.

59. Martinez-Argudo I, Jepson MA. Salmonella translocates across an in vitro M cell model independently of SPI-1 and SPI-2. Microbiology. 2008;154(Pt 12): 3887-94. https://doi.org/10.1099/mic.0.2008/021162-0.

60. Beaulieu JF. Differential expression of the VLA family of integrins along the crypt-villus axis in the human small intestine. J Cell Sci. 1992;102(Pt 3):427-36.

61. Esclatine A, Bellon A, Michelson S, Servin AL, Quero AM, Geniteau-Legendre M. Differentiation-dependent redistribution of heparan sulfate in epithelial intestinal Caco-2 cells leads to basolateral entry of cytomegalovirus. Virology. 2001;289(1):23-33. https://doi.org/10.1006/viro.2001.1122.

62. Singh B, Coffey RJ. Trafficking of epidermal growth factor receptor ligands in polarized epithelial cells. Annu Rev Physiol. 2014;76(1):275-300. https:// doi.org/10.1146/annurev-physiol-021113-170406

63. Criss AK, Casanova JE. Coordinate regulation of Salmonella enterica serovar Typhimurium invasion of epithelial cells by the Arp2/3 complex and rho GTPases. Infect Immun. 2003:71(5):2885-91. https://doi.org/10.1128/IAl.71.5.2 885-2891.2003.

64. Muller AJ, Kaiser P, Dittmar KE, Weber TC, Haueter S, Endt K, et al. Salmonella gut invasion involves TTSS-2-dependent epithelial traversal, basolateral exit, and uptake by epithelium-sampling lamina propria phagocytes. Cell Host Microbe. 2012;11(1):19-32. https://doi.org/10.1016/j. chom.2011.11.013.

65. Zhang YG, Wu S, Xia Y, Sun J. Salmonella infection upregulates the leaky protein claudin-2 in intestinal epithelial cells. PLoS One. 2013;8(3):e58606. https://doi.org/10.1371/journal.pone.0058606. 
66. Vazquez-Torres A, Jones-Carson J, Baumler AJ, Falkow S, Valdivia R, Brown W, et al. Extraintestinal dissemination of Salmonella by CD18-expressing phagocytes. Nature. 1999;401 (6755):804-8. https://doi.org/10.1038/44593.

67. Coombes BK, Coburn BA, Potter AA, Gomis S, Mirakhur K, Li Y, et al. Analysis of the contribution of Salmonella pathogenicity islands 1 and 2 to enteric disease progression using a novel bovine ileal loop model and a murine model of infectious enterocolitis. Infect Immun. 2005;73(11):7161-9. https:// doi.org/10.1128/IAI.73.11.7161-7169.2005.

68. Gusterson B, Cowley G, Smith JA, Ozanne B. Cellular localisation of human epidermal growth factor receptor. Cell Biol Int Rep. 1984;8(8):649-58. https://doi.org/10.1016/0309-1651(84)90045-6.

69. Kawakami-Kimura N, Narita T, Ohmori K, Yoneda T, Matsumoto K, Nakamura $\mathrm{T}$, et al. Involvement of hepatocyte growth factor in increased integrin expression on HepG2 cells triggered by adhesion to endothelial cells. $\mathrm{Br} J$ Cancer. 1997:75(1):47-53. https://doi.org/10.1038/bjc.1997.8.

70. Heffernan EJ, Wu L, Louie J, Okamoto S, Fierer J, Guiney DG. Specificity of the complement resistance and cell association phenotypes encoded by the outer membrane protein genes rck from Salmonella typhimurium and ail from Yersinia enterocolitica. Infect Immun. 1994;62(11):5183-6. https:// doi.org/10.1128/IAl.62.11.5183-5186.1994.

71. Alikhan NF, Zhou Z, Sergeant MJ, Achtman M. A genomic overview of the population structure of Salmonella. PLoS Genet. 2018;14(4):e1007261. https://doi.org/10.1371/journal.pgen.1007261.

72. Yoshida CE, Kruczkiewicz P, Laing CR, Lingohr EJ, Gannon VP, Nash JH, et al. The Salmonella In Silico typing resource (SISTR): an open web-accessible tool for rapidly typing and subtyping draft Salmonella genome assemblies. PLoS One. 2016;11(1):e0147101. https://doi.org/10.1371/journal.pone.0147101.

73. Nei M. Molecular Evolutionary Genetics. New-York: Columbia University Presss; 1987.

74. Paradis E. Pegas: an R package for population genetics with an integratedmodular approach. Bioinformatics. 2010;26(3):419-20. https://doi.org/10.1 093/bioinformatics/btp696.

75. Esko JD, Stewart TE, Taylor WH. Animal cell mutants defective in glycosaminoglycan biosynthesis. Proc Natl Acad Sci U S A. 1985;82(10): 3197-201. https://doi.org/10.1073/pnas.82.10.3197.

76. Casadaban MJ, Cohen SN. Analysis of gene control signals by DNA fusion and cloning in Escherichia coli. J Mol Biol. 1980;138(2):179-207. https://doi. org/10.1016/0022-2836(80)90283-1.

77. Simon R, Priefer U, Pühler A. A broad host range mobilization system for in vivo genetic engineering: transposon mutagenesis in gram negative bacteria. Bio/ Technology. 1983;1 (9):784-91. https://doi.org/10.1038/nbt1183-784.

78. Overton WR. Modified histogram subtraction technique for analysis of flow cytometry data. Cytometry. 1988;9(6):619-26. https://doi.org/10.1002/cyto. 990090617.

79. Burlaud-Gaillard J, Sellin C, Georgeault S, Uzbekov R, Lebos C, Guillaume JM, et al. Correlative scanning-transmission electron microscopy reveals that a chimeric flavivirus is released as individual particles in secretory vesicles. PLoS One. 2014;9(3):e93573. https://doi.org/10.1371/journal.pone.0093573.

\section{Publisher's Note}

Springer Nature remains neutral with regard to jurisdictional claims in published maps and institutional affiliations.

Ready to submit your research? Choose BMC and benefit from:
- fast, convenient online submission
- thorough peer review by experienced researchers in your field
- rapid publication on acceptance
- support for research data, including large and complex data types
- gold Open Access which fosters wider collaboration and increased citations
- maximum visibility for your research: over 100M website views per year
At BMC, research is always in progress.
Learn more biomedcentral.com/submissions

